\title{
Effect of welding parameters on microstructure, mechanical properties and residual stress fields of friction stirwelds on AA5086
}

\author{
H. Jamshidi Aval ${ }^{1 *}$, A. Loureiro ${ }^{2}$ \\ ${ }^{1}$ Department of Mechanical Engineering, Babol University of Technology, Shariati Avenue, Babol, P.O. Box 484, Iran \\ ${ }^{2}$ CEMUC, Department of Mechanical Engineering, University of Coimbra, \\ Rua Luís Reis Santos, 3030-788 Coimbra, Portugal
}

Received 12 November 2013, received in revised form 25 December 2013, accepted 2 May 2014

\begin{abstract}
The effect of tool rotational and welding speeds on the microstructure and mechanical properties of friction stir welded AA5086-O was studied. Optical metallography and scanning transmission electron microscopy were used to characterize the microstructure of different zones of welds. The relationship between residual stress profiles and local mechanical properties of different weld zones was studied using X-ray diffraction (XRD) and Digital Image Correlation (DIC), respectively. A lower speed ratio (tool rotational speed/tool traverse speed $-\omega / v$ ) reduced the grain size and increased hardness and tensile strength in the stir zone (SZ). The longitudinal and transversal residual stress profiles in the welds show a good correlation between the $(\omega / v)$ ratio (welding heat input) and local mechanical properties of different zones of FSWed joints. The weld produced with the highest heat input showed the lowest residual stress. Also, the residual stresses of different weld zones increased with their yield stress.
\end{abstract}

K e y words: friction stir welding, AA5086 aluminium alloys, microstructures, mechanical properties, residual stress

\section{Introduction}

As a solid-state joining technique, friction stir welding (FSW) - developed and patented by the Welding Institute (TWI) in 1991 [1] - is one of the most significant joining processes in welding aluminium alloys. The basic process of FSW is remarkably simple. During friction stir welding, the work-pieces to be joined are clamped to a backing plate. A specially shaped cylindrical tool rotates and slowly plunges into the workpiece until the tool shoulder comes into contact with the work-piece surface; then the rotating tool moves at a constant velocity along the welding line. Frictional heat generated by the rotary motion of the shoulder causes the material to soften, while the shoulder prevents the deformed material from flowing outward. As the pin tool moves along the joint, a weld joint is made by extrusion of thermally-softened material from the leading side to the trailing side of the rotating tool [2]. Friction stir welding is performed at much lower temperatures than conventional fusion welding, thus avoiding many of the environmental and safety issues associated with the latter.

Since its introduction, the material response during this process has been frequently studied. It was found that the microstructural and mechanical properties of friction stir welded aluminium alloys could be a result of several variables, including welding parameters, alloy composition, alloy temper, and the geometric parameters of tool and work-piece. In this regard, several studies on friction stir welding of 5000-series aluminium alloy have been carried out and published. For instance, James et al. [3] studied the effects of weld tool travel speed on the fatigue life of friction stir welds in 5083 aluminium alloy. It was reported that 'onion-skin' forging-type defects were not generally associated with fatigue crack initiation, but might act to reduce fatigue life by providing easy path ways between two fatigue cracks. Colligan et al. [4] studied the effects of travel speed on the transverse tensile 
properties and hardness distribution across the joint profile of FS welded 1-in. thick AA5083-H131 plate. It was discovered that the nugget had fine recrystallized grains (finer towards the TMAZ), contrasting with the elongated grains of the base metal. The TMAZ was narrow, displaying grain distortion oriented downward on the advancing side and upward on the retreating side. The authors stated that most tensile failures originated on the face of the weld and were propagated through the $\mathrm{SZ}$ on a $45^{\circ}$ plane. Hattingh et al. [5] studied the influence of FSW tool geometry on welding forces and tensile strength of welds on AA5083-H321. The influence of flute design, tool pin diameter and taper, and the pitch of any thread form were studied using a systematic tool profile matrix. They reported that optimized tool design can produce welds with $97 \%$ of the parent plate tensile strength. Also, it was found that the most successful tool designs are likely to incorporate three tapered flutes, a pin diameter taper, and have a thread form with a pitch of around $10 \%$ of the pin diameter. Jamshidi et al. $[6,7]$ studied the influence of tool geometry, as well as tool travelling and rotational speeds, on thermo-mechanical and microstructural properties in friction stir welding of 5086 aluminium alloy. They reported that frictional heat generation was comparable to that resulting from plastic dissipation. The grain size of the TMAZ decreased with lower heat input per unit length during FSW. Hirata et al. [8] studied the effect of FSW parameters on the microstructure of the SZ and the mechanical property of FS-welded 5083 aluminium alloy. They showed that the ductility of welds was improved by grain size refinement in the SZ with the decrease in friction heat flow. Chen et al. [9] studied the flow of the shear layer around the tool pin during friction stir welding of AA5083-O. They stated that a portion of the shear zone material adjacent to the pin formed a layer and detached itself from the pin on the trailing-retreating side during each revolution; finally, these detached layers formed the SZ. Also, it was observed that the velocity of the newly detached shear layer was very low compared with the pin periphery velocity. Lombard et al. [10] studied the process parameters of residual stress profiles in friction stir welds on 5083-H321 aluminium alloy. They reported that the residual stresses were generally tensile in the weld region, with balancing compressive stresses in the parent plate. Also, they showed that the width of the tensile stress region and the maximum value of the tensile residual stress exhibited a linear dependence on heat input. Leitão et al.[11, 12] studied the weldability and plastic properties across different weld zones of AA5083 friction stir welds. They used a shear testing procedure to evaluate strength and plastic properties of weld zones, reporting that AA5083-H111 displayed poor weldability during FSW of similar joints. Kumar et al. [13] studied the process forces and heat input
Table 1. The AA5086-O chemical composition (wt.\%) and mechanical properties

\begin{tabular}{|c|c|c|c|c|c|c|}
\hline $\mathrm{Mg}$ & Mn & $\mathrm{Cu}$ & $\mathrm{Cr}$ & $\mathrm{Si}$ & $\mathrm{Fe}$ & $\mathrm{Al}$ \\
\hline 4.12 & 0.447 & 0.030 & 0.105 & 0.244 & 0.343 & Balancing \\
\hline \multicolumn{3}{|c|}{ Yield stress (MPa) } & \multicolumn{3}{|c|}{ Tensile strength (MPa) } & $\%$ \\
\hline \multicolumn{3}{|c|}{112} & \multicolumn{3}{|c|}{253} & 26 \\
\hline
\end{tabular}

during FSW of AA5083. They reported that tool rotational speed, welding speed and tool shoulder diameter were significant parameters influencing axial force and heat input, while longitudinal force was significantly influenced by welding speed and probe diameter.

Although several studies have been conducted to study the different aspects of friction stir welding of 5000-series aluminium alloys, there remains a need for a detailed study in order to understand microstructural and mechanical response in FSW of these alloys. In this study, the effects of welding parameters in friction stir welding of AA5086 are considered, and the resultant microstructures in the weld zone and their mechanical properties are studied. The relationship between residual stress profile and local mechanical properties of different zones, examined using the $\mathrm{X}$-ray diffraction (XRD) residual stress measurement method and Digital Image Correlation (DIC) technique, respectively, is also analyzed.

\section{Experimental procedures}

In this study, the $5 \mathrm{~mm}$ thick AA5086-O plate with the composition and mechanical properties given in Table 1 was used. $150 \mathrm{~mm}$ long and $50 \mathrm{~mm}$ wide rectangular specimens were used. Single-pass friction stir butt welds were made in position control by a milling machine. The tool was positioned at a tilt angle of $1^{\circ}$ and plunged to a depth of $4.9 \mathrm{~mm}$. A tool made of H13 steel with a shoulder diameter of $20 \mathrm{~mm}$, a $2^{\circ}$ conical cavity and a threaded conical pin $4.8 \mathrm{~mm}$ in length was used in the experiments, as shown in Fig. 1. Tool rotational speeds of 700, 900, 1100 and $1300 \mathrm{rpm}$ and linear speeds of 40, 80, 120 and $160 \mathrm{~mm} \mathrm{~min}^{-1}$ were used in the experiments.

Subsequently, both microstructures and mechanical properties of the welded samples were evaluated. A modified Poulton's reagent containing $30 \mathrm{ml} \mathrm{HCl}$, $40 \mathrm{ml} \mathrm{HNO}_{3}, 2.5 \mathrm{ml} \mathrm{HF}, 12 \mathrm{~g} \mathrm{CrO}_{3}$ and $42.5 \mathrm{ml} \mathrm{H}_{2} \mathrm{O}$ was used to reveal the microstructural evolution of different zones of the samples. TEM was used to study the various structures associated with FSW. Specimens were made by spark-eroding $3 \mathrm{~mm}$ discs from $200 \mu \mathrm{m}$ thick slices from the weld face and the base 
Ta b le 2. Effect of welding parameters on grain size of SZ

\begin{tabular}{cccc}
\hline Welding speed $v\left(\mathrm{~mm} \mathrm{~min}^{-1}\right)$ & Rotational speed $\omega(\mathrm{rpm})$ & $\omega / v$ ratio $\left(\mathrm{rev} \mathrm{mm}{ }^{-1}\right)$ & SZ grain size $(\mu \mathrm{m})$ \\
\hline 80 & 900 & 11.25 & 8.2 \\
80 & 1100 & 13.75 & 10.4 \\
120 & 1100 & 9.17 & 7.6 \\
120 & 1300 & 10.83 & 8.0 \\
\hline
\end{tabular}

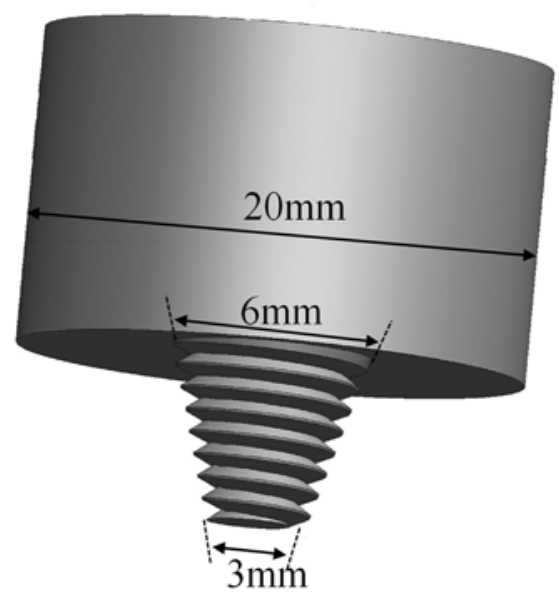

Fig. 1. Geometry of the tool used in this study.

metal. The discs were mechanically ground to a thickness of about $150 \mu \mathrm{m}$, followed by polishing with a twin jet electro polishing system using an electrolyte of $25 \% \mathrm{HNO}_{3}$ in ethanol, and a polishing voltage of $12 \mathrm{~V}$. Specimens were cleaned and stored in pure ethanol. Vickers micro-hardness was measured on metallographically prepared specimens $2.5 \mathrm{~mm}$ from the weld root using a $100 \mathrm{gf}$ load and a holding time of $15 \mathrm{~s}$. The tensile properties of the FSW joints were evaluated by preparing sub-size specimens (of $25 \mathrm{~mm}$ gauge length with $5 \mathrm{~mm}$ thickness) along the transversal direction to the weld line according to ASTM E8M [14]. The tensile tests were carried out at room temperature and at a cross head speed of $5 \mathrm{~mm} \mathrm{~min}^{-1}$. Furthermore, the deformation behaviour of transversal tensile samples was measured using a Digital Image Correlation (DIC) method and an Aramis 3D 5M optical system (GOM GmbH). Finally, residual stress measurements were performed by means of the X-ray diffraction (XRD) technique. The residual stress measurements were carried out using $\operatorname{CrK} \alpha$ radiation with the $\mathrm{X}$-ray tube operating at $20 \mathrm{kV}$ and $4 \mathrm{~mA}$ target current. For each joint, longitudinal and transversal residual stress distributions were evaluated transversely to the weld direction.

\section{Results and discussion}

The present study only shows the analysis of the cross-section of the welds that have been carried out within satisfactory parameters, i.e. which do not prompt the formation of defects, specifically those made with the following parameters: $(900 \mathrm{rpm}$, $\left.80 \mathrm{~mm} \mathrm{~min}^{-1}\right),\left(1100 \mathrm{rpm}, 80 \mathrm{~mm} \mathrm{~min}^{-1}\right),(1100 \mathrm{rpm}$, $120 \mathrm{~mm} \mathrm{~min}^{-1}$ ) and $\left(1300 \mathrm{rpm}, 120 \mathrm{~mm} \mathrm{~min}^{-1}\right)$. The cross-section of the weld $\left(900 \mathrm{rpm}, 80 \mathrm{~mm} \mathrm{~min}^{-1}\right.$ ) is shown in Fig. 2a. Neither cracks nor porosity are visible in the image, illustrating the good quality of welds mentioned above. It is apparent that although both the advancing side and the retreating side of welds form a boundary with the weld nugget, the boundary in the retreating side is rather unclear. The same behaviour was observed for the other welds. The microstructures of the weld nugget and the thermo-mechanically affected zone (TMAZ) for the sample $\left(900 \mathrm{rpm}, 80 \mathrm{~mm} \mathrm{~min}^{-1}\right.$ ) are shown in Figs. 2b-g. Microstructures of the weld nugget evolving into fine equiaxed grains under every FSW condition were observed. As shown in Table 2 and Figs. 3a-c, the recrystallized grain size of the SZ increased with a higher rotational speed $(\omega)$ at constant welding speed $(v)$; for instance, the grain size in the stir zone of the sample welded with $900 \mathrm{rpm}$ and $80 \mathrm{~mm} \mathrm{~min}^{-1}$ was $8.2 \mu \mathrm{m}$, while in the weld produced with $1100 \mathrm{rpm}$ and $80 \mathrm{~mm} \mathrm{~min}^{-1}$ it was $10.4 \mu \mathrm{m}$. On the other hand, by increasing welding speed at a constant rotational speed, the grain size in the nugget decreased. It has been reported that frictional heat generation $\left(Q_{\mathrm{t}}\right)$ by the shoulder is an important factor in FSW operations; also, the final microstructures in the weld zone are strongly influenced by this phenomenon $[6,15]$. According to several researchers, heat generation $\left(Q_{\mathrm{t}}\right)$ is directly influenced by tool rotational speed $(\omega)[15$, 16]. Furthermore, the FSW tool moves during FSW and thus, heat input during FSW should be related to the $Q_{\mathrm{t}} / v$ ratio. Therefore, the ratio of speeds $(\omega / v)$ represents in relative terms the amount of heat input per unit length of weld. As Table 2 and Figs. 3a-c show, the grain size of SZ was increased by increasing the speed ratio. This phenomenon has already been observed in FSW of several materials and is linked to the increase of heat input, achieved due to increased rotational speed or reduced traverse speed $[16,17]$. Figures 2c,d show that the TMAZ is composed of elongated grains "squeezed" by the tool. These grains did not recrystallize due to insufficient temperature during welding. The difference in shape and grain size 

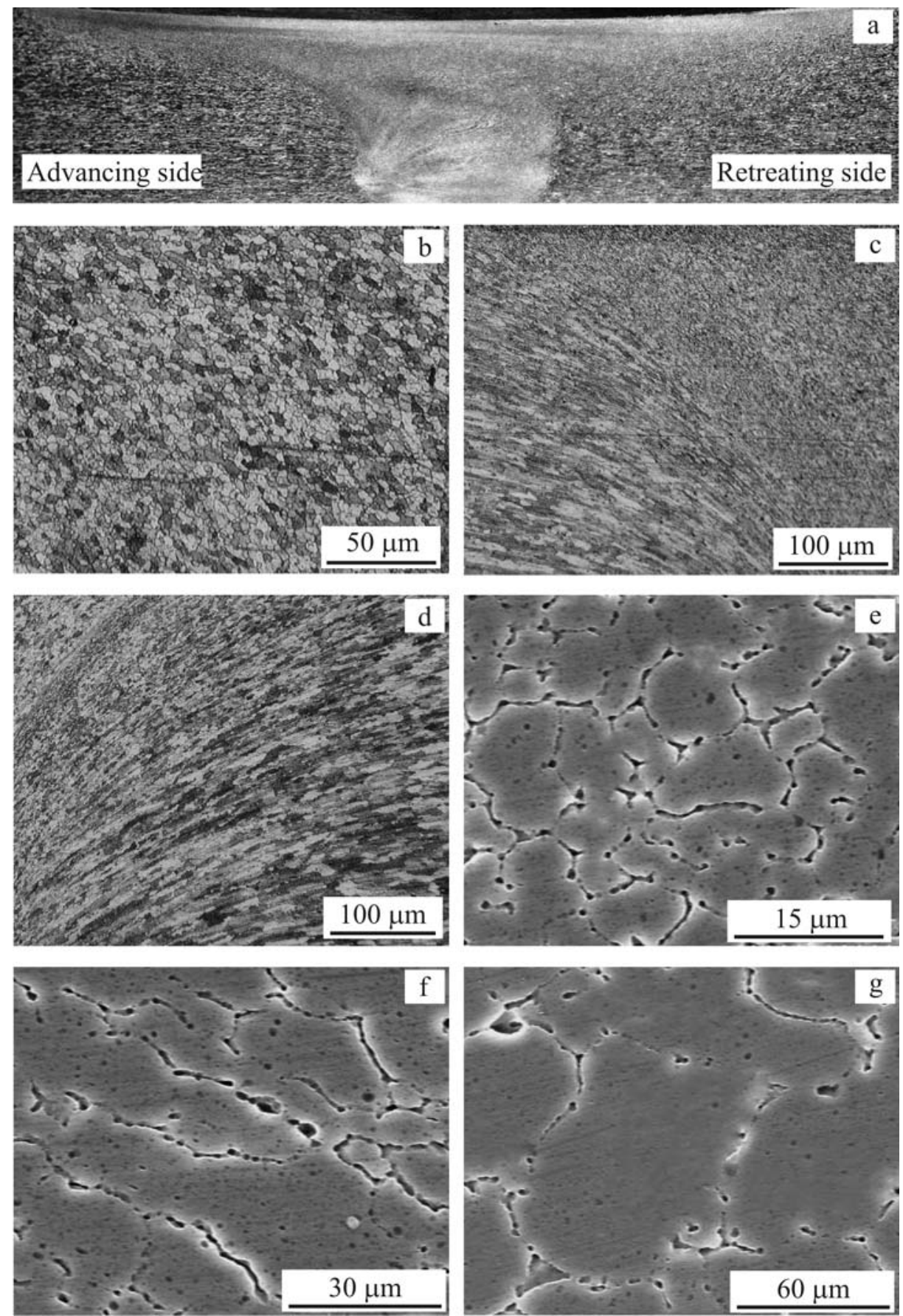

Fig. 2. Macrostructure and microstructure of different zones for joint welded at $900 \mathrm{rpm}$ and $80 \mathrm{~mm} \mathrm{~min}^{-1}$; a) macrostructure of weld; optical image of: b) SZ; c) TMAZ of advancing side; d) TMAZ of retreating side; SEM image of: e) SZ; f) TMAZ of advancing side and g) base material.

between the nugget, TMAZ and BM is evident in SEM images (Figs. 2e-g).

Figure 4 shows the horizontal hardness profile across the joints measured at $2.5 \mathrm{~mm}$ from the root face in the sample $900 \mathrm{rpm}, 80 \mathrm{~mm} \mathrm{~min}^{-1}$. The BM shows a Vickers micro-hardness of about $61 \mathrm{HV}_{0.1}$. As shown in the figure, the hardness values measured in the weld are higher than the base material mean hardness. The increase in hardness within the SZ can be explained by grain size strengthening using the Hall-Petch relation and the influence of the submicron fragmented particles or dispersoids which block the dislocation movement (dislocation looping, Orowan hardening). It has been reported that in the absence of considerable hardening, the Hall-Petch equation is reformulated in terms of the hardness, HV, through the following relationship $[8]$ : 

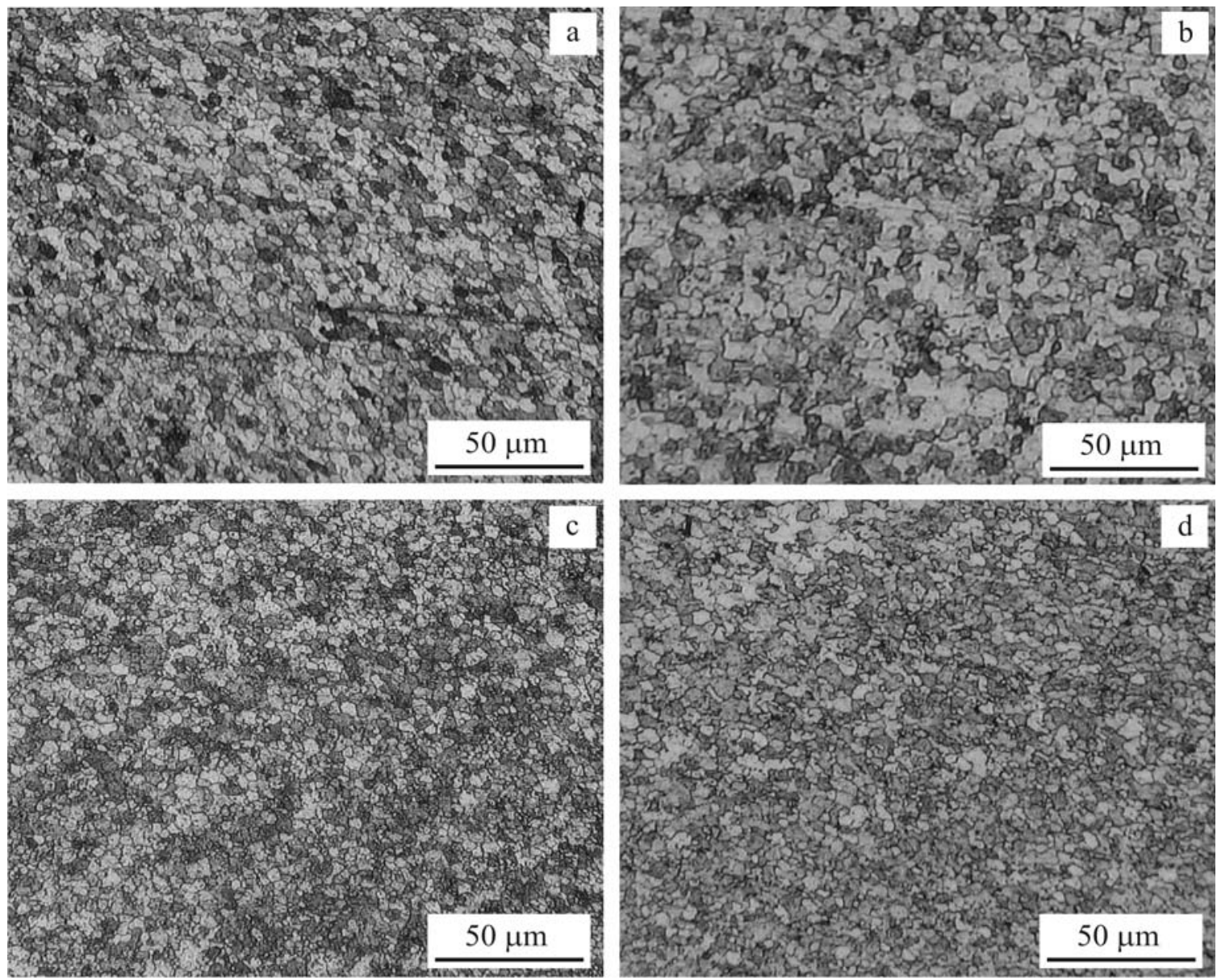

Fig. 3. Microstructure of stir zone: a) sample (900 rpm, $\left.80 \mathrm{~mm} \mathrm{~min}^{-1}\right)$, b) $\left(1100 \mathrm{rpm}, 80 \mathrm{~mm} \mathrm{~min}^{-1}\right)$, c) (1100 rpm, $\left.120 \mathrm{~mm} \mathrm{~min}^{-1}\right)$, d) (1300 $\left.\mathrm{rpm}, 120 \mathrm{~mm} \mathrm{~min}^{-1}\right)$.

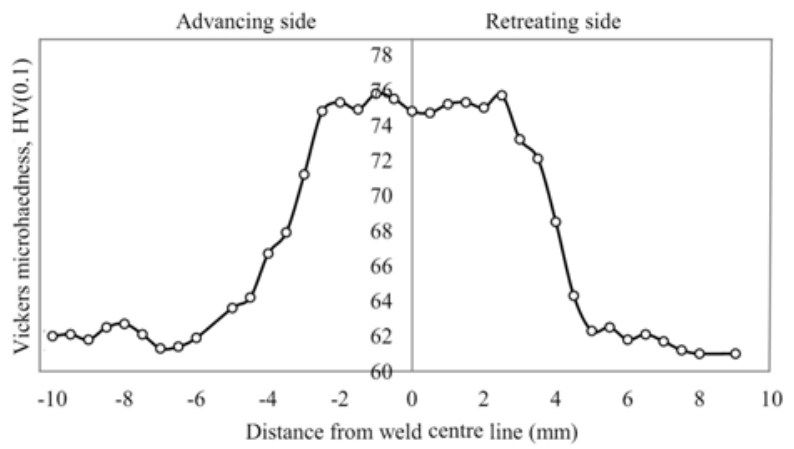

Fig. 4. Micro-hardness profile of sample $(900 \mathrm{rpm}, 80 \mathrm{~mm}$ $\left.\min ^{-1}\right)$.

$$
\mathrm{HV}=H_{0}+K_{\mathrm{H}} d^{-0.5},
$$

where $d$ is the grain size and $H_{0}$ and $K_{\mathrm{H}}$ are the appropriate constants associated with the hardness measurements. Thus, hardness increased with the decrease in grain size. Figure 5 shows TEM bright-field images of the SZ and base material grains for samples (1100 rpm, $80 \mathrm{~mm} \mathrm{~min}^{-1}$ ) and (1300 rpm,
$120 \mathrm{~mm} \mathrm{~min}^{-1}$ ). The maximum micro-hardness of the $\mathrm{SZ}$ in the samples $\left(1100 \mathrm{rpm}, 80 \mathrm{~mm} \mathrm{~min}^{-1}\right)$ and $\left(1300 \mathrm{rpm}, 120 \mathrm{~mm} \mathrm{~min}^{-1}\right.$ ) are $78.5 \mathrm{HV}_{0.1}$ and 74.2 $\mathrm{HV}_{0.1}$, respectively. The dislocation density and submicron particle specification (size and number density) are almost identical in these samples, but the SZ grain size is clearly different. TEM observation in the SZ shows the structures of AA5086 aluminium alloy, which are recrystallized grains after FSW. The hardness profile shows that hardness of SZ is higher than that in the TMAZ and slightly decreases in the base material. This may be attributed to small recrystallized grain size of SZ and higher dislocation density as shown in Figs. 5a-c. As shown in Figs. 5e-f, the weld nugget contains iron rich (gray) and $\mathrm{Mg}_{2} \mathrm{Si}$ (black) dispersoids uniformly distributed within the grains. According to Figs. 5a-c, particles in the SZ have greater density and are thinner $(0.04-1 \mu \mathrm{m})$ than those in the base material with a particle size of $0.5-10 \mu \mathrm{m}$. Stirring and heating during friction stir welding result in the fracture of particles or re-precipitation of new particles in the weld nugget. However, these particles in the weld nugget are incoherent with the matrix, and their strengthening mechanism is Orowan loop- 

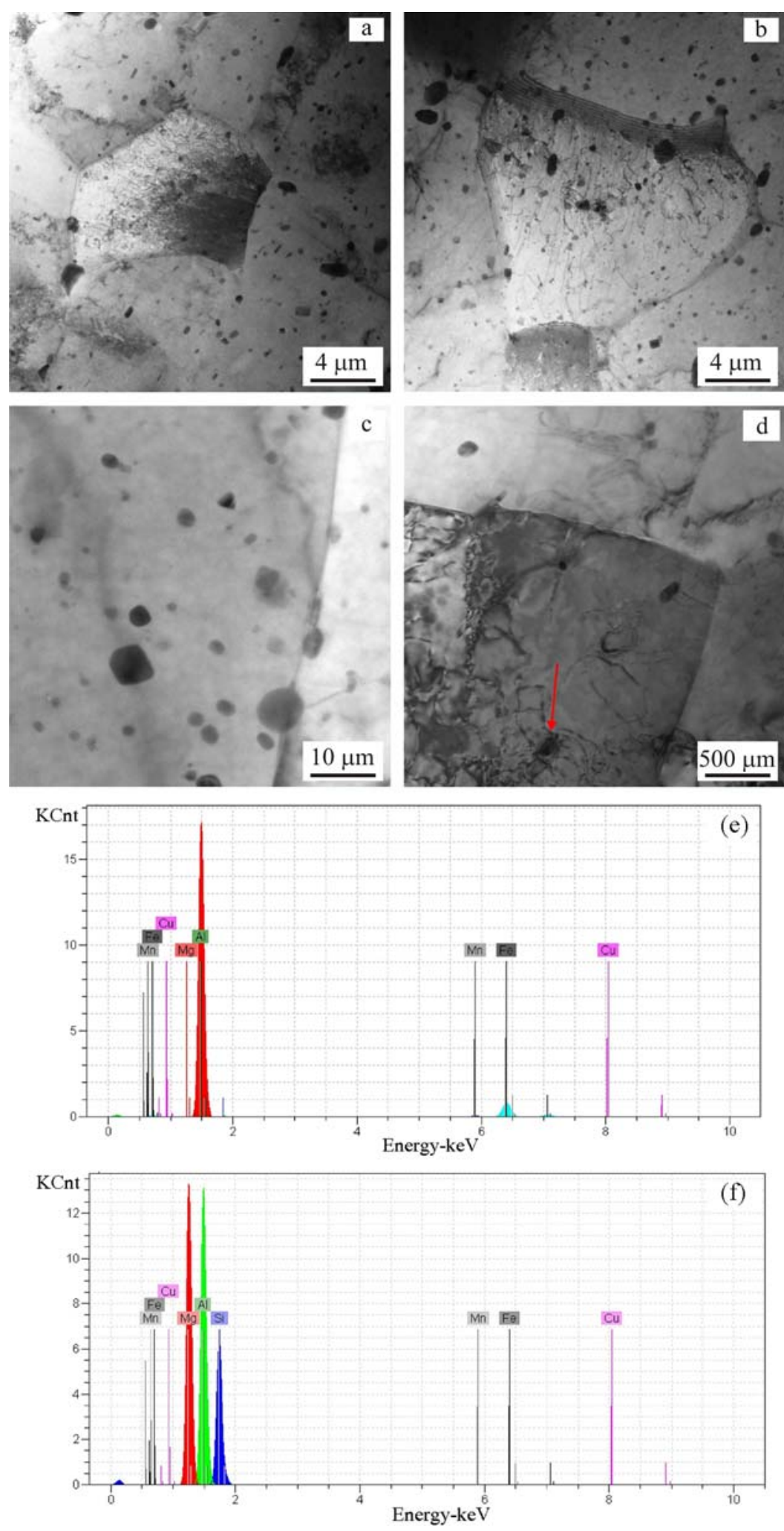

Fig. 5. Sub-structural features of different zones: a) SZ of sample (1300 rpm, $\left.120 \mathrm{~mm} \mathrm{~min}^{-1}\right)$, b) SZ of sample (1100 rpm, $80 \mathrm{~mm} \mathrm{~min}^{-1}$ ), c) base material, d) Orowan loop, e) EDS spectrum of grey particles, f) EDS spectrum of black particles.

ing [18]. Figure 5d shows Orowan looping in the SZ of the $\left(1100 \mathrm{rpm}, 80 \mathrm{~mm} \mathrm{~min}^{-1}\right)$ sample.

The results of residual stress measured in the sample (1100 rpm, $120 \mathrm{~mm} \mathrm{~min}^{-1}$ ) are shown in Fig. 6. The longitudinal residual stresses in the regions which correspond to the nugget of the welds have a tensile 
Ta b le 3. Effect of welding speeds ratio $(w / v)$ on maximum tensile residual stress

\begin{tabular}{ccc}
\hline$\omega / v$ ratio $\left(\mathrm{rev} \mathrm{mm}^{-1}\right)$ & Max. longitudinal residual stress $(\mathrm{MPa})$ & Max. transversal residual stress $(\mathrm{MPa})$ \\
\hline 11.25 & 76.9 & 25.4 \\
13.75 & 73.8 & 22.8 \\
9.17 & 84.5 & 29.3 \\
10.83 & 81.3 & 27.6 \\
\hline
\end{tabular}

nature. However, for longer distances from the weld residual stresses gradually become compressive. Similar behaviour occurs in the transversal residual stress profiles with one notable difference: longitudinal tensile residual stresses are approximately three times higher than transversal tensile residual stresses. Maximum tensile residual stress in the weld centre line is lower than that at the SZ/TMAZ interface, for both longitudinal and transversal stresses. This may be due to the stirring action of the FSW tool relieving some of the tensile residual stress in the SZ. Localized heat from welding and plastic deformation of the weld nugget causes residual stress in welded samples. However, plastic deformation of the weld nugget at high temperature relieves the compressive stresses, but in the surrounding areas the strength gradient causes tensile stress due to the temperature gradient. As the weld cools to room temperature, the compressive residual stress arises in regions away from the weld balancing tensile residual stress at the weld centre line. Furthermore, residual stress profiles across the welds are essentially distributed symmetrically on both the advancing and retreating sides. This fluctuation may be due to low temperature and strain differences in these two sides during FSW. In addition, the weld produced with the highest heat input per unit of length shows the lowest values of residual stress (Table 3 ). This may be due to steeper temperature gradients and reduced stress relaxation times during welding, with lower heat input. Besides, the softest material displays the lowest residual stress, i.e. higher grain size $=$ lower hardness, and yield strength $=$ lower residual stress.

Figure 7 also shows the strain contour maps and the local stress-strain graph of different weld sub-zones for the sample $\left(900 \mathrm{rpm}, 80 \mathrm{~mm} \mathrm{~min}^{-1}\right)$, calculated using the Sub-Pixel Digital Image Correlation (SPDIC) technique. The stress-strain graph depicts the behaviour of the weld materials. The stress-strain graphs are drawn at different locations in order to identify the area of maximum strain according to the method explained in [19]. The strain map in Fig. 7 corresponds to strain distribution at maximum load. The stress-strain curve suggests differences between the SZ of FSW and the parent metal specifically that the microstructural properties of the material are different due to welding. Figure 7a shows that the weld is in "overmatch" condition (i.e. the yield stress of the SZ is higher than that of the base material), as illustrated

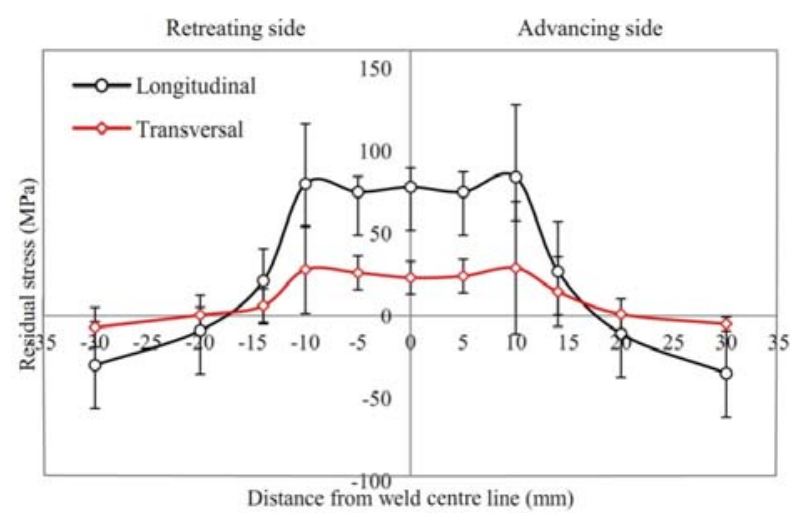

Fig. 6. Residual stresses profile of sample (1100 rpm, $\left.120 \mathrm{~mm} \mathrm{~min}^{-1}\right)$.
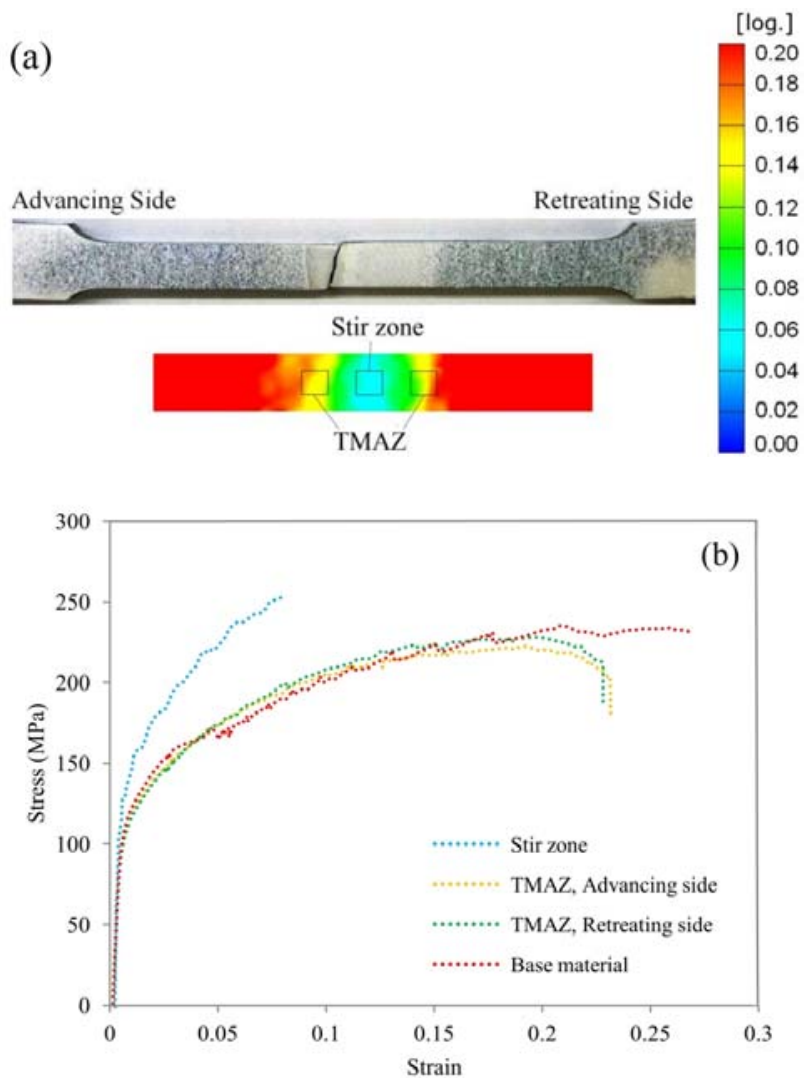

Fig. 7. a) The strain maps, b) the local mechanical properties of different weld sub-zones for the sample welded with $900 \mathrm{rpm}, 80 \mathrm{~mm} \mathrm{~min}^{-1}$. 
by lower strain in SZ (see colour code). This is because the base material is in the annealed condition, temper condition $\mathrm{O}$. When aluminium is in other temper conditions, for example T6, the weld overmatch condition may not be attained. As shown in Fig. 7a, a fracture in tensile samples occurs in the TMAZ of the advancing side. According to the hardness profile, the relatively steep hardness gradient in TMAZ leads to localized stress and eventually fractures in this zone. There is a relation between local mechanical properties and residual stress profiles. The areas with higher yield strength show higher tensile residual stress. In other words, the residual stresses in the welded zone increase with increasing yield stress in those zones. Another important implication of Fig. 7 is that the area with lower strain exhibits greater hardness.

\section{Conclusions}

The influence of friction stir welding parameters on microstructure, mechanical properties and residual stress fields of similar friction stir welds on AA5086 was examined by optical, scanning and transmission electron microscopy, micro-hardness and tensile testing, as well as by X-ray diffraction (XRD) technique. The following results were obtained:

1. The grain size in the SZ increased with the tool rotational/traverse speed ratio $(\omega / v)$.

2 . The hardness of the SZ increased with the decrease in $(\omega / v)$ ratio because of the grain size refinement.

3. The results show that for all samples the longitudinal residual stresses around the weld centre line are tensile and gradually become compressive beyond the heat affected zone.

4. The weld areas with higher yield strength show higher tensile residual stress.

5 . The highest longitudinal tensile residual stress, of about $84.5 \mathrm{MPa}$, was associated to the weld produced using the lowest $(\omega / v)$ ratio.

\section{References}

[1] Thomas, W. M., Nicholas, E. D., Needham, J. C., Murch, M. G., Templesmith, P., Dawes, C. J.: International Patent Application No. PCT/GB92102203 and Great Britain Patent Application No. 9125978.8, 1991.

[2] Nandan, R., Debroy, T., Bhadeshia, H. K. D. H.: Progress in Materials Science, 35, 2008, p. 980. doi:10.1016/j.pmatsci.2008.05.001
[3] James, M. N., Hattingh, D. G., Bradley, G. R.: International Journal of Fatigue, 25, 2003, p. 1389. doi:10.1016/S0142-1123(03)00061-6

[4] Colligan, K., Ucok, I., McTernan, K., Konkol, P. J., Pickens, J. R.: Proceedings of the 3rd International Symposium on Friction Stir Welding. Cambridge, TWI Ltd. 2001.

[5] Hattingh, D. G., Blignault, C., Van Niekerk, T. I., James, M. N.: Journal of Materials Processing Technology, 203, 2008, p. 46. doi:10.1016/j.jmatprotec.2007.10.028

[6] Jamshidi Aval, H., Serajzadeh, S., Kokabi, A. H.: The International Journal of Advanced Manufacturing Technology, 52, 2011, p. 531. doi:10.1007/s00170-010-2752-x

[7] Jamshidi Aval, H., Serajzadeh, S., Kokabi, A. H.: Journal of Mechanical Engineering Science, Part C, 224, 2011, p. 1. doi:10.1243/09544062JMES2267

[8] Hirata, T., Oguri, T., Hagino, H., Tanaka, T., Chung, S. W., Takigawa, Y., Higashi, K.: Materials Science and Engineering A, 456, 2007, p. 344. doi:10.1016/j.msea.2006.12.079

[9] Chen, Z. W., Pasang, T., Qi, Y.: Materials Science and Engineering A, 474, 2008, p. 312. doi:10.1016/j.msea.2007.05.074

[10] Lombard, H., Hattingh, D. G., Steuwer, H., James, M. N.: Materials Science and Engineering A, 501, 2009, p. 119. doi:10.1016/j.msea.2008.09.078

[11] Leitão, C., Louro, R., Rodrigues, D. M.: Materials and Design, 37, 2012, p. 402. doi:10.1016/i.matdes.2012.01.031

[12] Leitão, C., Costa, M. I., Khanijomdi, K., Rodrigues, D. M.: Materials and Design, 51, 2013, p. 968. doi:10.1016/j.matdes.2013.04.100

[13] Kumar, R., Singh, K., Pandey, S.: Transactions of Nonferrous Metals Society of China, 22, 2012, p. 288. doi:10.1016/S1003-6326(11)61173-4

[14] ASTM E8-04, Standard Test Methods for Tension Testing of Metallic Materials. West Conshohocken, ASTM International 2004. doi:10.1520/E0008_E0008M

[15] Schmidt, H., Hattel, J., Wert, J.: Modelling and Simulation in Materials Science and Engineering, 12, 2004, p. 143. doi:10.1088/0965-0393/12/1/013

[16] Galvão, I., Leal, R. M., Rodrigues, D. M., Loureiro, A.: Journal of Materials Processing Technology, 213, 2013, p. 129. doi:10.1016/j.jmatprotec.2012.09.016

[17] Hao, H. L., Ni, D. R., Huang, H., Wang, D., Xiao, B. L., Nie, Z. R., Ma, Z. Y.: Materials Science \& Engineering A, 559, 2013, p. 889. doi:10.1016/j.msea.2012.09.041

[18] Mahon, G. J., Marshall, G. J.: JOM, 48, 1996, p. 39. doi:10.1007/BF03222965

[19] Leitão, C., Galvão, I., Leal, R. M., Rodrigues, D. M.: Materials and Design, 33, 2012, p. 69. doi:10.1016/j.matdes.2011.07.009 